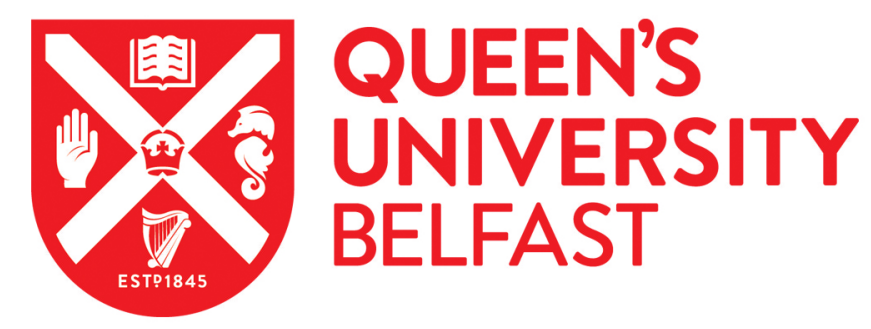

\title{
Exploring the Impact of Illness Perceptions, Self-efficacy, Coping Strategies, and Psychological Distress on Quality of Life in a Post-stroke Cohort
}

Minshall, C., Ski, C. F., Apputhurai, P., Thompson, D. R., Castle, D. J., Jenkins, Z., \& Knowles, S. R. (2021). Exploring the Impact of Illness Perceptions, Self-efficacy, Coping Strategies, and Psychological Distress on Quality of Life in a Post-stroke Cohort. Journal of Clinical Psychology in Medical Settings, 28, 174-180. https://doi.org/10.1007/s10880-020-09700-0

\section{Published in:}

Journal of Clinical Psychology in Medical Settings

\section{Document Version:}

Peer reviewed version

Queen's University Belfast - Research Portal:

Link to publication record in Queen's University Belfast Research Portal

\section{Publisher rights}

Copyright 2020 Springer. This work is made available online in accordance with the publisher's policies. Please refer to any applicable terms of use of the publisher.

\section{General rights}

Copyright for the publications made accessible via the Queen's University Belfast Research Portal is retained by the author(s) and / or other copyright owners and it is a condition of accessing these publications that users recognise and abide by the legal requirements associated with these rights.

Take down policy

The Research Portal is Queen's institutional repository that provides access to Queen's research output. Every effort has been made to ensure that content in the Research Portal does not infringe any person's rights, or applicable UK laws. If you discover content in the Research Portal that you believe breaches copyright or violates any law, please contact openaccess@qub.ac.uk. 


\section{Exploring the Common Sense Model and interrelationships between illness}

2 perceptions, coping strategies, psychological distress and quality of life in a

3 post-stroke cohort

4

5 Catherine Brasier (Catherine.Brasier@myacu.edu.au) ${ }^{1,2}$

6 Pragalathan Apputhurai (papputhurai@swin.edu.au) ${ }^{3}$

7 Chantal F Ski (Chantal.Ski@unimelb.edu.au) 2,4,5

8

9

David R Thompson (David.Thompson@unimelb.edu.au) $)^{4,5,6}$

David J Castle (David.Castle@svha.org.au) 2,4

Simon R Knowles (sknowles@swin.edu.au) $)^{2,3,4 *}$ Melbourne, VIC 3122, Australia

*Corresponding author

Running head: Validation of the CSM in a post-stroke cohort. depression, anxiety and quality of life interest in our research.

Collaborative Research Networks (CRN) program.

${ }^{1}$ The Australian Catholic University, Faculty of Health Sciences, Melbourne, VIC 3000

2St. Vincent's Hospital, Mental Health Service, Melbourne, VIC 3065, Australia

${ }^{3}$ Swinburne University, Department of Psychology, Faculty of Health, Arts and Design,

${ }^{4}$ The University of Melbourne, Department of Psychiatry, Melbourne, VIC 3010, Australia

${ }^{5}$ School of Nursing and Midwifery, Queen's University Belfast, Belfast, United Kingdom

${ }^{6}$ Australian Centre for Heart Health, Royal Melbourne Hospital, Melbourne, Australia

${ }^{4}$ St. Vincent's Hospital, Department of Neurology, Melbourne, VIC 3065, Australia

Keywords: Stroke, common sense model, illness perceptions, coping, self-efficacy,

Acknowledgements: The authors would like to thank all the participants for the support and

Sources of funding: This work was supported through the Australian Government's

Disclosure statement: The authors have no competing interests to report. 
30 Exploring the Impact of Illness Perceptions, Self-Efficacy, Coping Strategies, and

31 Psychological Distress on Quality of Life in a Post-Stroke Cohort

32 Running head: Validation of the CSM in a post-stroke cohort.

33 Keywords: Stroke, common sense model, illness perceptions, quality of life, anxiety,

34 depression.

35 Tables and Figures

36 Table 1. Pearson's correlation and descriptive statistics of the scales

37 Table 2. Summary of the regression analysis between the five predictor variables on QoL

38 Figure 1. Multiple mediation between illness perception and QoL

43 Acknowledgment: The authors would like to thank all the participants for the support and

44 interest in our research.

45 Sources of funding: This work was supported through the Australian Government's

46 Collaborative Research Networks (CRN) program.

47 Disclosure statement: The authors have no competing interests to report. 


\section{Abstract}

49 This study evaluated the mediating role of self-efficacy, coping, depression and anxiety on

50 the relationship between illness perceptions and quality of life in stroke survivors $(n=72 ; 32$

51 females; mean [SD] age 65.09 [14.14] years; male mean [SD] age 69.83[11.81]). Illness

52 perceptions (Brief Illness Perceptions Questionnaire; BIPQ), coping styles (Carver Brief COPE

53 scale; B-COPE), depression/anxiety (Hospital Anxiety and Depression Scale; HADS), self-

54 efficacy (General Self-Efficacy Scale; GSE) and quality of life (Assessment of quality of life;

55 AQOL-6D) were analysed. Correlation analyses showed illness perception, maladaptive

56 coping, self-efficacy, depression and anxiety to have a significant negative relationship with

57 quality of life. Mediation analyses showed that while maladaptive coping and self-efficacy

58 did not mediate the relationship between illness perception and quality of life, depression

59 and anxiety did. The final model explained $76.74 \%$ of the variance in quality of life.

60 Although based on a relatively small sample size, these results provide evidence for the

61 important role of psychosocial factors in quality of life in post-stroke cohorts.

62

63 
The Common Sense Model (CSM) developed by Leventhal and colleagues (1980) can be used to understand the psychosocial health of important chronic diseases, such as stroke, by establishing the relationship between illness symptoms and individual outcomes (e.g., quality of life[QoL]) which are mediated by illness perceptions and coping style. In the past, the CSM has been applied to numerous chronic illnesses including gastrointestinal disorders (Knowles, Wilson, Connell, \& Kamm, 2011), diabetes (Breland, McAndrew, Burns, Leventhal, \& Leventhal, 2013) and arthritis (Knowles et al., 2016). However, the CSM has been applied to stroke survivors in only few studies (Hagger \& Orbell, 2003; Klinedinst, Dunbar \& Clark, 2012; Phillips, Diefenbach, Abrams \& Horowitz, 2015).

The CSM proposes that disease activity shares an integral link with the individual's perception of their illness, referred to as 'illness perceptions' (Leventhal, Phillips \& Burns, 2016). In CSM, illness perceptions refer to the cognitive and emotional perceptions that individuals develop in response to becoming aware of a threat to their health (Leventhal et al., 2016). Concisely described by Broadbent et al. (2006), illness perceptions are comprised of five dimensions: chronicity (is the illness chronic, acute or cyclical?); consequence (how much does the illness impact on my physical and psychosocial well-being?); causes (what factors caused or influenced the illness?); identity (how is one impacted by having an illness?); and cure/control (can the illness be cured or controlled?). The concept of 'coping' is also central to the CSM. According to Lazarus and Folkman

84 (1984), individuals mediate stress through behaviour and cognition. In CSM, 'adaptive coping' strategies seek to change the situation (e.g., planning, problem solving), while 
'maladaptive coping' strategies seek to regulate emotional distress (e.g., praying, avoiding)

87 (Lazarus \& Folkman, 1984). Considering this literature, the CSM may be able to provide new insights into the relationship between illness parameters and psychosocial outcomes in stroke survivors. Stroke is the second highest cause of mortality and the third leading cause of disability worldwide (Feigin, Norrving \& Mensah, 2017). Stroke is a neurological condition that occurs when a blockage or bleed in the brain results in oxygen deprivation and associated cell death (Sacco et al., 2013). Stroke can produce myriad symptoms including cognitive, motor/sensory and language impairments (Sacco et al., 2013). In addition, the detrimental impact of stroke on survivor's psychosocial health is widely noted (Frincu, Lupsa, \& Stefanescu, 2016; Wang \& Wang, 2013). Globally, the economic cost of stroke between 2014 and 2015 exceeded \$34 billion in the US (Centres for Disease Control and Prevention, 2019) and €45 billion in the European Union (Stroke Alliance for Europe, 2016). With stroke healthcare costs exceeding \$606 million in Australia in 2008-2009 (Australian Institute of Health and Welfare, 2013) the physical, emotional and fiduciary costs of stroke are deeply concerning.

Depression, anxiety and reduced QoL as well as other psychosocial maladies are common following a stroke (Ayerbe, Ayis, Wolfe \& Rudd, 2013). In fact, recent systematic reviews (Mitchell et al., 2017; Schöttke \& Giabbiconi, 2015) estimate that one-third of stroke survivors experience depression, whilst a further $25 \%$ experience clinical anxiety (Chun,

106 Whiteley, Dennis, Mead \& Carson, 2018). Evidence suggests that psychosocial outcomes 107 such as depression, anxiety and QoL affect each other (Tang, Lau, Mok, Ungvari \& Wong, 108 2013; van Mierlo et al.; 2014 Volz, Möbus, Letsch \& Werheid, 2016). Although these 
relationships are not well understood, evidence suggests that depression is linked to poor

110 QoL (Zhang et al., 2017). Meanwhile, self-efficacy has been shown to affect QoL and depression (Robinson-Smith, Johnston \& Allen, 2000; Volz, Möbus, Letsch \& Werheid, 2016). and the importance of psychosocial mediators in health, this study sought to explore the

114 CSM in stroke survivors. It was hypothesized that, aligned with CSM, self-efficacy, coping styles, depression and anxiety would act as mediators between illness perceptions and QoL.

\section{Methods}

117 Participants were recruited as part of the Stroke and Carer Optimal Health Program (SCOHP)

118 trial, the details of which have been reported elsewhere (Braiser et a. 2016). An a priori

119 power analysis using GPower (version 3.1) with an effect size 0.15 , error probablity alpha

$120 \quad 0.05$ and power of 0.80 indicated a minimum of 68 individuals to predict QoL with seven

121 predictor variables. The sample of 72 participants surpassed this requirement.

\section{Compliance with ethical standards}

123 This trial was approved by a Melbourne Metropolitan Human Research Ethics Committee

124 (HREC-A 031/12). Written informed consent was obtained from all participants. The authors 125 declare no potential conflicts of interest with respect to the research, the authorship, 126 and/or publication of this article.

\section{Materials}

128 Brief Illness Perceptions Questionnaire (BIPQ) (Broadbent, Petrie, Main \& Weinman, 129 2006). 
The BIPQ is a 9-item questionnaire evaluating emotional/ cognitive representations of

131 illness across eight dimensions: emotional response, consequences, timeline, personal control, treatment control, identity, concern and understanding (Broadbent, 2006). Items were assessed according to a 11-point rating scale. For example, "How much does your

134 illness affect your life: 0 [not at all] - 10 [severely affects my life]" (Broadbent et al., 2006).

135 Reliability analysis was conducted with if the item deleted until the Cronbach's alpha above

136 0.7. After removing 2 items (control over illness and helpfulness of treatment), remaining

137 items demonstrated good internal consistency (0.71). The illness perception scale score was

138 created by attaining the average of the subscales, with higher scores reflecting more

139 negative emotional and cognitive representations of illness. Meta-analysis of the BIPQ has

140 demonstrated construct validity in other chronic diseases such as diabetes (Broadbent, et

141 al., 2015).

142 Carver Brief Coping Questionnaire (Brief-COPE) (Carver, 1997).

143 The Brief-COPE is comprised of 14-subscale questionnaires, with two items per subscale. A 144 4-point rating scale is used, for example: " 1 [I haven't been doing this at all] to 3 [I've been 145 doing this a lot]" (Carver et al., 1997). Due to sample size constraints, the coping subscales 146 could not be derived by factor analysis. Instead, subscales were based on those reported by

147 Carver et al. (1989). Maladaptive coping was based on 12 items (self-distraction, denial,

148 substance use, behavioural disengagement, venting, self-blame) and had good internal 149 consistency (0.71). Emotion-focused coping was based on 10 items (emotional support, 150 positive reframing, humor, acceptance, religion) and had a good internal consistency (0.74).

151 Finally, problem-focused coping was based on 6 items (active coping, instrumental support, 
planning) and demonstrated good internal consistency of (0.85). All three subscales were created as the average of the respective items.

\section{General Self-efficacy Scale (GES) (Schwarzer \& Jerusalem, 1995)}

The General Self-Efficacy Scale is a 10-item measure which assesses an individual's belief that they can overcome challenges and situations in their own life, utilising a 4-point scale:

"1 [Not at all true]" to "4 [Exactly true]" (Schwarzer \& Jerusalem, 1995, p.38). Items are summed giving a score range of 10 to 40; higher scores signify greater levels of self-efficacy (Schwarzer \& Jerusalem, 1995). The self-efficacy scale had good internal consistency (0.89).

Hospital Anxiety and Depression Scale (HADS) (Snaith, 2003)

The HADS is a 14-item self-report questionnaire that assesses depression (7 items) and anxiety ( 7 items) rated over the previous seven days. Questions are assessed via a 4-point Likert scale. For example, "I feel tense or 'wound up"” $0=[$ not at all] to $3=[$ most of the time] (Snaith, 2003, p. 2). Scores between 16 and 21 indicate the presence of a mood disorder (Snaith, 2003). The anxiety and depression subscales had good internal consistency ( 0.84 and 0.83 respectively). The HADS has been validated for use in stroke survivors, reporting $60 \%$ specificity and $80 \%$ sensitivity (Burton \& Tyson, 2015).

Assessment of Quality of Life-6 Dimensions (AQoL-6D) (Allen, Inder, Lewin, Attia \& Kelly, 2013).

The AQoL-6D is a multi-attribute self-reported questionnaire that provides a multidimensional assessment of health-related quality (Allen, Inder, Lewin, Attia \& Kelly, 2013). It comprises 20 items which assess 6 domains of QoL (relationships - 3 items, independent living -4 items, coping -3 items, mental health -4 items, senses -3 items and

174 pain -3 items). Items have between 4 to 6 response options which can be combined to 
175 provide an overall score of QoL; higher scores suggest greater impairment in QoL. The QoL

176 scale had good internal consistency (0.91).

\section{Statistical analysis}

178 Prior to conducting multiple regression modeling, the relevant assumptions of this statistical 179 analysis strategy were tested. The assumption of singularity was met, as the independent 180 variables were not a combination of other independent variables. An examination of correlations (see Table 1) revealed that no independent variables were highly correlated.

182 The assumptions of multicollinearity, normality, linearity and homoscedasticity were all satisfied (Hair, Black, Babin \& Anderson, 2018; Pallant, 2001). Mediation analyses were carried out using PROCESS macro (version 3.4) for SPSS (Preacher \& Hayes, 2008).

\section{Results}

Participants were 72 stroke survivors (32 females; mean [SD] age 65.09 [14.14] years; male mean [SD] age 69.83[11.81]), of whom 61 percent were married, 7 percent were defacto, 8 percent were divorced, 2 percent were separated, 17 percent were single, 3 percent were widowed and 2 percent identified their relationship as 'other'. Mean [SD] time since stroke was 33 months [28.2].

Table 1 shows the descriptive and correlational analyses of the study variables.

192 Illness perceptions and maladaptive coping were significantly positively correlated, as well as both having significant positive correlations with anxiety and depression and significant negative correlations with QoL and self-efficacy. Emotion-focused coping had a positive correlation with problem-focused coping and a negative correlation with depression, both relationships were significant. Problem-focused coping had a significant positive correlation with self-efficacy. Maladaptive coping had a significant positive relationship with 
depression/anxiety and the other two coping strategies, and a significant negative correlation with self-efficacy and QoL. In addition, QoL had a significant negative correlation with depression and anxiety, and a significant positive correlation with self-efficacy. As emotion and problem-focused coping did not have a significant correlation with QoL, they were not included in further analysis.

To evaluate the study hypothesis that that self-efficacy, coping styles, depression and anxiety act as mediators between illness perceptions and QoL, separate regression analyses were performed to investigate whether each variable predict QoL. As shown in Table 2, illness perception, self-efficacy, maladaptive coping, depression and anxiety each had a unique effect on QoL.

INSERT TABLE 2 HERE

Mediation analyses with 5000 bootstrap samples were conducted to examine the

211 potential roles of maladaptive coping, self-efficacy, depression and anxiety as mediators between illness perceptions and QoL. As shown in Figure 1, consistent with full mediation, illness perception was no longer a significant predictor of QoL after the mediator variables

214 were included in the model. Maladaptive coping and self-efficacy did not mediate the relationship between illness perception and QoL. This suggests that depression and anxiety

216 fully mediate the relationship between QoL and illness perception. The final model was

217 found to account for $76.74 \%$ of the variance in QoL. 
Whilst the global prevalence of stroke is increasing (Gorelick, 2019), medical advances are

221 leading to improved survival rates (Warner, Harrington, Sacco \& Elkind, 2019; Seminog,

222 Scarborough, Wright, Rayner \& Goldacre, 2019). While higher survival rates are positive, it is

223 also well-established that post-stroke cohorts report greater rates of depression and anxiety compared to healthy control groups (Campbell Burton et al., 2012; Cumming, Blomstrand,

Skoog \& Linden; Lincoln et al., 2013) as well as poorer QoL (Abubakar, \& Isezuo., 2012;

Franzen-Dahlin \& Laska, 2012). Given this, the identification of psychosocial variables that

can be utilised by psychological interventions to target and promote QoL in stroke survivors is essential. The evaluation of well established psychosocial models of health outcomes, such as the CSM, provide a strong theoretical and practical basis to identify and evaluate psychosocial variables. maladaptive anxiety and depression mediated the relationship between illness perceptions and QoL. This reflects the premise that mental health is a key marker of QoL (Lincoln et al., 2013; Northcott, Moss, Harrison, \& Hilari, 2015). Although not found to act as a mediator, self-efficacy was found to be predicted by illness perceptions. Coping styles are complex and have been conceptualised in numerous ways to exemplify their diverse impact. In CSM, coping styles are essential to one's welfare and are thought to determine key outcomes (Lazarus \& Folkman., 1984.) In support of other CSM-based research, coping (specifically maladaptive coping), was predicted by illness perceptions (Knowles et al, 2019). The findings that maladaptive coping, and not other forms of coping (emotion- and problem-focused) was predicted by illness perceptions is consistent with past research (Knowles et al, 2017; 
242 Knowles et al, 2019). While the influence of QoL by maladaptive coping was not significant,

243 these findings reflect the more influential role of maladaptive coping than adaptive coping

244 styles. It should also be acknowledged that although not tested in this study, both self-

245 efficacy and maladaptive coping may also have a direct impact on anxiety and depression.

246 While this is the first study to provide partial evidence for the CSM in a stroke cohort, it is

247 not without limitations. The first limitation was that no measure of health status was

248 collected, despite being a key predictor variable of illness perceptions in the CSM. The small

249 number of participants and self-reported nature the questionnaires, may bias the results

250 and only reflect the perceptions of participants and not the wider post-stroke population.

251 The study design was cross-sectional and therefore true causal (mediation) relationships

252 could not be evaluated; nor could bi-directional pathways be evaluated. Future research

253 should seek to replicate and extend the current findings by utilisng more advanced

254 statistical approaches such as structural equation modeling (SEM), to better control for

255 measurement error and inter-item correlations, and assess for multiple

256 simultaneous mediational relationships. An extended CSM in a post-stroke cohort could also

257 explore the potential mediating role of other psychosocial variables which have been found

258 to be associated with post-stroke outcomes, like QoL, including optimism (Kim, Park \&

259 Peterson, 2011) and carer support (King, Hartke \& Houle, 2010). While acknowledging these

260 limitations, the study has identified several potential psychosocial variables, specifically

261 illness perceptions, maladaptive coping, self-efficacy, and depression and anxiety which

262 could be targeted through psychological interventions such as cognitive behaviour therapy

263 (CBT) the promote QoL in a post-stroke cohort. 
265 Along with higher rates of anxiety and depression, post stroke cohorts are also at risk of

266 reduced QoL. Based on the CSM, this study explored the potential mediational role of self-

267 efficacy, coping strategies, and anxiety and depression between illness perceptions and QoL

268 in a post-stroke cohort. The findings suggest that that along illness perceptions, anxiety and

269 depression should be targets for modification using well-established psychological

270 interventions such as CBT to enhance QoL in post-stroke cohorts.

$271 \quad$ Funding

272 Supported by the Australian Government's Collaborative Research Networks (CRN) 273

274 
276 277

278

Abubakar, S. \& Isezuo, S. (2012). Health related quality of life of stroke survivors: Experience of a stroke unit. International Journal of Biomedical Science, 8, 183-187. no doi.

Allen, J., Inder, K. J., Lewin, T. J., Attia, J. R., \& Kelly, B. J. (2013). Construct validity of the assessment of Quality of Life - 6D (AQoL-6D) in community samples. Health and Quality of Life Outcomes, 11, 61-61. doi: 10.1186/1477-7525-11-61

Australian Institute of Health and Welfare. (2013). Stroke and its management in Australia: An update (Vol. Cat. no. CVD 61). Canberra: AlHW.

Ayerbe, L., Ayis, S., Wolfe, C. D., \& Rudd, A. G. (2013). Natural history, predictors and outcomes of depression after stroke: Systematic review and meta-analysis. British Journal of Psychiatry, 202, 14-21. doi: 10.1192/bjp.bp.111.107664

Brasier, C., Ski, C. F., Thompson, D. R., Cameron, J., O’Brien, C., ... Castel, D. (2016) The Stroke and Carer Optimal Health Program (SCOHP) to enhance psychosocial health: Study protocol for a randomised controlled trial. Trials. 17:466. doi: 10.1186/s13063016-1559-y

Breland, J. Y., McAndrew, L. M., Burns, E., Leventhal, E. A. \& Leventhal, H. (2013). Using the Common Sense Model of self-regulation to review the effects of self-monitoring of blood glucose on glycemic control for non-insulin-treated adults with type 2 diabetes. Diabetes Educator, 39, 541-549. doi: 10.1177/0145721713490079.

Broadbent, E., Petrie, K. J., Main, J., \& Weinman, J. (2006). The Brief Illness Perception Questionnaire. Journal of Psychosomatic Research, 60, 631-637. doi: 2005.10.020 
Broadbent, E., Wilkes, C., Koschwanez, H., Weinman, J., Norton, S., \& Petrie, K. (2015). A systematic review and meta-analysis of the Brief Illness Perception Questionnaire. Psychology \& Health, 30(11), 1361-1385. doi. $10.1080 / 08870446.2015 .1070851$

Burton, L. J., \& Tyson, S. (2015). Screening for mood disorders after stroke: A systematic review of psychometric properties and clinical utility. Psychological Medicine, 45, 2949. doi: $10.1017 /$ S0033291714000336

Campbell Burton, C., Murray, J., Holmes, J., Astin, F., Greenwood, D., \& Knapp, P. (2012). Frequency of anxiety after stroke: A systematic review and meta-analysis of observational studies. International Journal of Stroke, 8, 545-559. doi: 10.1111/j.1747-4949.2012.00906

Carver, C. (1997). You want to measure coping but your protocol's too long: Consider the brief COPE. International Journal of Behavioral Medicine, 4, 92-100. doi: 10.1207/s15327558ijbm0401_6

Carver, C. S., Scheier, M. F., \& Weintraub, J. K. (1989). Assessing coping strategies: A theoretically based approach. Journal of Personality and Social Psychology, 56, 267283.

Centres fo Disease Control and Prevention, Stroke Facts, accessed December 2019, Retrieved from https://www.cdc.gov/stroke/facts.htm

Chun, H.-Y. Y., Whiteley, W. N., Dennis, M. S., Mead, G. E., \& Carson, A. J. (2018). Anxiety after stroke: The importance of subtyping. Stroke, 49, 556-564. doi: 10.1161/STROKEAHA.117.020078 
Cumming, T. B., Blomstrand, C., Skoog, I., \& Linden, T. (2016). The high prevalence of anxiety disorders after stroke. The American Journal of Geriatric Psychiatry, 24, 154-160. doi: https://doi.org/10.1016/j.jagp.2015.06.003

Feigin, V. L., Norrving, B., \& Mensah, G. A. (2017). Global burden of stroke. Circulation Research, 120, 439-448. doi: 10.1161/CIRCRESAHA.116.308413

Franzen-Dahlin, A, \& Laska, A. (2012). Gender differences in quality of life after stroke and TIA: A cross-sectional survey of out-patients. Journal of Clinical Nursing, 21, 23862368. doi: 10.1111/j.1365-2702.2011.04064.x.

Frincu, R., Lupsa, L., \& Stefanescu, C. (2016). Pathophysiological mechanisms in post-stroke depression. Psychosocial and economic implications of patient rehabilitation. Bulletin of Integrative Psychiatry, 22, 31. no doi.

Gorelick, P. (2019). The global burden of stroke: Persistent and disabling. The Lancet Neurology, 18, 417-418. doi: 10.1016/S1474-4422(19)30030-4

Hagger, M. S., \& Orbell, S. (2003). A meta-analytic review of the common-sense model of illness representations. Psychology \& Health, 18, 41-184. doi: $10.1080 / 088704403100081321$

Hair Jr., J. F., Black, W. C., Babin, B. J. \& Anderson R. E. (2018). Multivariate Data Analysis. Englewood Cliffs, NJ: Prentice-Hall.

Kim, E. S., Park, N., \& Peterson, C. (2011). Dispositional optimism protects older adults from stroke: The Health and Retirement Study. Stroke, 42, 2855-2859. 
Klinedinst, N. J., Dunbar, S. B., \& Clark, P. C. (2012). Stroke survivor and informal caregiver perceptions of poststroke depressive symptoms. Journal of Neuroscience Nursing, 44, 72-81. doi: 10.1097/JNN.0b013e3182477944

Knowles, S. R., Nelson, E. A., Castle, D. J., Salzberg, M. R., Choong, P. F. M., \& Dowsey, M. M. (2016). Using the common sense model of illness to examine interrelationships between symptom severity and health outcomes in end-stage osteoarthritis patients. Rheumatology, 55, 1066-1073. doi: 10.1093/rheumatology/kew022

Knowles, S. R., Wilson, J. L., Connell, W. R., \& Kamm, M. A. (2011). Preliminary examination of the relations between disease activity, illness perceptions, coping strategies, and psychological morbidity in Crohn's disease guided by the common sense model of illness. Inflamatory Bowel Disease, 17, 1-7. doi: 10.1002/ibd.21650

Knowles, S., Austin, D., Sivanesan, S., Tye-Din, J., Leung, C., Wilson, J., ... Hebbard, G. (2017). Relations between symptom severity, illness perceptions, visceral sensitivity, coping strategies and well-being in irritable bowel syndrome guided by the common sense model of illness. Psychology, Health \& Medicine, 22, 524-534. doi: $10.1080 / 13548506.2016 .1168932$

Knowles, S., Apputhurai, P., O'Brien, C., Ski, C., Thompson, D., \& Castle, D. (2019). Exploring the relationships between illness perceptions, self-efficacy, coping strategies, psychological distress and quality of life in a cohort of adults with diabetes mellitus. Psychology, Health \& Medicine, 1-15. doi: 10.1080/13548506.2019.1695865. 
Korpershoek, C., van der Bijl, J., \& Hafsteinsdóttir, T. B. (2011). Self-efficacy and its influence on recovery of patients with stroke: A systematic review. Journal of Advanced Nursing, 67, 1876-1894. doi: 10.1111/j.1365-2648.2011.05659.x

Lazarus, R. S., \& Folkman, S. (1984). Stress, appraisal, and coping. New York: Springer.

Leventhal, H., Meyer, D., \& Nerenz, D. (1980). The common sense model of illness danger. In S. Rachman (Ed.), Contributions to medical psychology (pp.7-30). New York: Pergamon Press.

Leventhal, H., Phillips, L., \& Burns, E. (2016). The Common-Sense Model of self-regulation (CSM): A dynamic framework for understanding illness self-management. Journal of Behavioral Medicine, 39, 935-946. doi: 10.1007/s10865-016-9782-2

Lincoln, N. B., Brinkmann, N., Cunningham, S., Dejaeger, E., De Weerdt, W., Jenni, W., ... De Wit, L. (2013). Anxiety and depression after stroke: A 5 year follow-up. Disability \& Rehabilitation, 35, 140-145. doi: 10.3109/09638288.2012.691939

Mitchell, A. J., Sheth, B., Gill, J., Yadegarfar, M., Stubbs, B., Yadegarfar, M., \& Meader, N. (2017). Prevalence and predictors of post-stroke mood disorders: A meta-analysis and meta-regression of depression, anxiety and adjustment disorder. General Hospital Psychiatry, 47, 48-60. doi: 10.1016/j.genhosppsych.2017.04.001

King, R. B., Hartke, R. J., \& Houle, T. T. (2010). Patterns of relationships between background characteristics, coping, and stroke caregiver outcomes. Topics in Stroke Rehabilitation, 17, 308-317. doi: 10.1310/tsr1704-308 
Northcott, S., Moss, B., Harrison, K., \& Hilari, K. (2015). A systematic review of the impact of stroke on social support and social networks: Associated factors and patterns of change. Clinical Rehabilitation, 30, 811-831. doi: 10.1177/0269215515602136

Pallant, J. (2001). SPSS survival manual: A step by step guide to data analysis using SPSS for Windows version 10. Buckingham: Open University Press.

Phillips, L. A., Diefenbach, M. A., Abrams, J., \& Horowitz, C. R. (2015). Stroke and TIA survivors' cognitive beliefs and affective responses regarding treatment and future stroke risk differentially predict medication adherence and categorised stroke risk. Psychology \& Health, 30, 218-232. doi: 10.1080/08870446.2014.964237

Preacher. K., \& Andrew, H. (2008). Asymptotic and resampling strategies for assessing and comparing indirect effects in multiple mediator models, Behavior Research Methods, 40, 879. No doi.

Robinson-Smith, G., Johnston, M. V., \& Allen, J. (2000). Self-care self-efficacy, quality of life, and depression after stroke. Archives of Physical Medicine Rehabilitation, 81, 460464. doi: $10.1053 / \mathrm{mr} .2000 .3863$

Sacco, R. L., Kasner, S. E., Broderick, J. P., Caplan, L. R., Connors, J. J., Culebras, A., . . Vinters, H. V. (2013). An updated definition of stroke for the 21st century: A statement for healthcare professionals from the American Heart Association/American Stroke Association. Stroke, 44, 2064-2089. doi: 10.1161/STR.0b013e318296aeca

Schöttke, H., \& Giabbiconi, C., M. (2015). Post-stroke depression and post-stroke anxiety: Prevalence and predictors. International Psychogeriatrics, 27, 1805-1812. doi: $10.1017 / \mathrm{S} 1041610215000988$ 
403

404

405

406

407

408

409

410

411

412

413

414

415

416

417

418

419

420

421

422

423

424

Schwarzer, R., \& Jerusalem, M. (1995). Generalized Self-Efficacy Scale. In J. Weinman, S. Wright, \& M. Johnston (Eds.), Measures in health psychology: a user's portfolio. Causal and control beliefs. (pp. 5-37). NFER Nelson: Windsor.

Seminog, O., Scarborough, P., Wright, F., Rayner, M., \& Goldacre, M. (2019). Determinants of the decline in mortality from acute stroke in England: Linked national database study of 795869 adults. BMJ, 365, L1778. doi: 10.1136/bmj.I1778

Snaith, R. P. (2003). The Hospital Anxiety and Depression Scale. Health \& Quality of Life Outcomes, 1, 29. doi: 10.1186/1477-7525-1-29

Stroke Alliance for Europe. (2016). The burden of stroke in Europe. SAFE: London.

Tang, W. K., Lau, C. G., Mok, V., Ungvari, G. S., \& Wong, K. S. (2013). Impact of anxiety on health-related quality of life after stroke: A cross-sectional study. Archives of Physical Medicine and Rehabilitation, 94, 2535-2541. doi: 10.1016/j.apmr.2013.07.012

van Mierlo, M. L., Schröder, C., van Heugten, C. M., Post, M. W. M., de Kort, P. L. M., \& Visser-Meily, J. M. A. (2014). The influence of psychological factors on health-related quality of life after stroke: A systematic review. International Journal of Stroke, 9, 341-348. doi: 10.1111/ijs.12149

Volz, M., Möbus, J., Letsch, C., \& Werheid, K. (2016). The influence of early depressive symptoms, social support and decreasing self-efficacy on depression 6 months poststroke. Journal of Affective Disorders, 206, 252-255. doi: 10.1016/j.jad.2016.07.041

Wang, L., \& Wang, K. S.. (2013). Age differences in the associations of behavioral and psychosocial factors with stroke. Neuroepidemiology, 41, 94-100. doi: $10.1159 / 000350018$ 
425 Warner, J. J., Harrington, R. A., Sacco, R. L., \& Elkind, M. S. (2019). Guidelines for the early

426

427

428

429

430

431

432

433

434

435

436

437 438

439

440

441 management of patients with acute ischemic stroke: 2019 update to the 2018 guidelines for the early management of acute ischemic stroke. Stroke, 50, 33313332. no doi.

Zhang, L., Sui, M., Yan, T., You, L., Li, K., \& Gao, Y. (2017). A study in persons later after stroke of the relationships between social participation, environmental factors and depression. Clinical Rehabilitation, 31, 394-402. doi: 10.1177/0269215516641300

Zhang, Maochen, Hong, Liwen, Zhang, Tianyu, Lin, Yun, Zheng, Sichang, Zhou, Xiaolin, ... Zhong, Jie. (2016). Illness perceptions and stress: Mediators between disease severity and psychological well-being and quality of life among patients with Crohn's disease. Patient Preference and Adherence, 10, 2387-2396. doi: 10.2147/PPA.S118413 
Appendix 1.

443 Table 1. Pearson's correlation and descriptive statistics of the scales

\begin{tabular}{|c|c|c|c|c|c|c|c|c|c|}
\hline Variable & 1 & 2 & 3 & 4 & 5 & 6 & 7 & $\begin{array}{l}\text { Cronbach's } \\
\text { alpha }\end{array}$ & $\begin{array}{c}\text { Mean } \\
\text { (SD) }\end{array}$ \\
\hline $\begin{array}{l}\text { 1. Illness } \\
\text { perceptions }\end{array}$ & - & & & & & & & 0.71 & $\begin{array}{c}6.49 \\
(2.28)\end{array}$ \\
\hline $\begin{array}{l}\text { 2.Maladaptive } \\
\text { coping }\end{array}$ & $0.33^{* *}$ & - & & & & & & 0.71 & $\begin{array}{c}1.65 \\
(1.96)\end{array}$ \\
\hline $\begin{array}{l}\text { 3. Emotion- } \\
\text { focused } \\
\text { coping }\end{array}$ & -0.06 & $0.20^{*}$ & - & & & & & 0.74 & $\begin{array}{c}2.26 \\
(0.54)\end{array}$ \\
\hline $\begin{array}{l}\text { 4. Problem- } \\
\text { focused } \\
\text { coping }\end{array}$ & 0.19 & $0.33^{* *}$ & $0.66 * *$ & - & & & & 0.85 & $\begin{array}{c}2.58 \\
(0.80)\end{array}$ \\
\hline $\begin{array}{l}\text { 5. Self- } \\
\text { efficacy }\end{array}$ & $-0.35^{*}$ & $-0.35 * *$ & 0.14 & $0.19 *$ & - & & & 0.89 & $\begin{array}{l}30.04 \\
(5.27)\end{array}$ \\
\hline 6. Anxiety & $0.49 * *$ & $0.51^{* *}$ & -0.03 & 0.14 & $-0.42^{* *}$ & - & & 0.84 & $\begin{array}{c}7.16 \\
(4.07\end{array}$ \\
\hline 7. Depression & $0.48^{* *}$ & $0.41^{* *}$ & $-.23 *$ & -0.09 & $-0.46 * *$ & $0.63^{* *}$ & - & 0.83 & $\begin{array}{c}6.33 \\
(4.24)\end{array}$ \\
\hline $\begin{array}{l}\text { 8. Quality of } \\
\text { Life }\end{array}$ & $-0.56 * *$ & $-0.51 * *$ & 0.03 & -0.06 & $0.53^{* *}$ & $-0.69 * *$ & $-0.77 * *$ & 0.91 & $\begin{array}{c}0.63 \\
(0.21)\end{array}$ \\
\hline
\end{tabular}

$444 \quad$ Note: ${ }^{*} p<.05$ and ${ }^{* *} p<.001$. 
445

Table 2. Summary of the regression analysis between the five predictor variables on QoL.

\begin{tabular}{lcccccc}
\hline Variable & $\boldsymbol{B}$ & $\boldsymbol{S E}$ & $\boldsymbol{B}$ & $\boldsymbol{t}$ & $\boldsymbol{C l}$ & $\boldsymbol{R}^{\mathbf{2}}$ \\
\hline Illness perception & -0.06 & 0.01 & $-0.56^{* *}$ & -5.22 & {$[-0.09,-.04]$} & $31.6 \%$ \\
Maladaptive Coping & -0.28 & 0.05 & $-0.51^{* *}$ & -6.20 & {$[-0.37,-.19]$} & $25.7 \%$ \\
Self-efficacy & 0.03 & 0.01 & $0.53^{* *}$ & 6.77 & {$[0.02, .03]$} & $28.0 \%$ \\
Anxiety & -0.04 & 0.01 & $-0.69^{* *}$ & -10.57 & {$[-0.04,-0.03]$} & $48.0 \%$ \\
Depression & -0.04 & 0.01 & $-0.77^{* *}$ & -13.06 & {$[-.05,-.03]$} & $58.5 \%$ \\
\hline
\end{tabular}

446 Note: ${ }^{* *} p<.001$.

447

448

449

450

451 


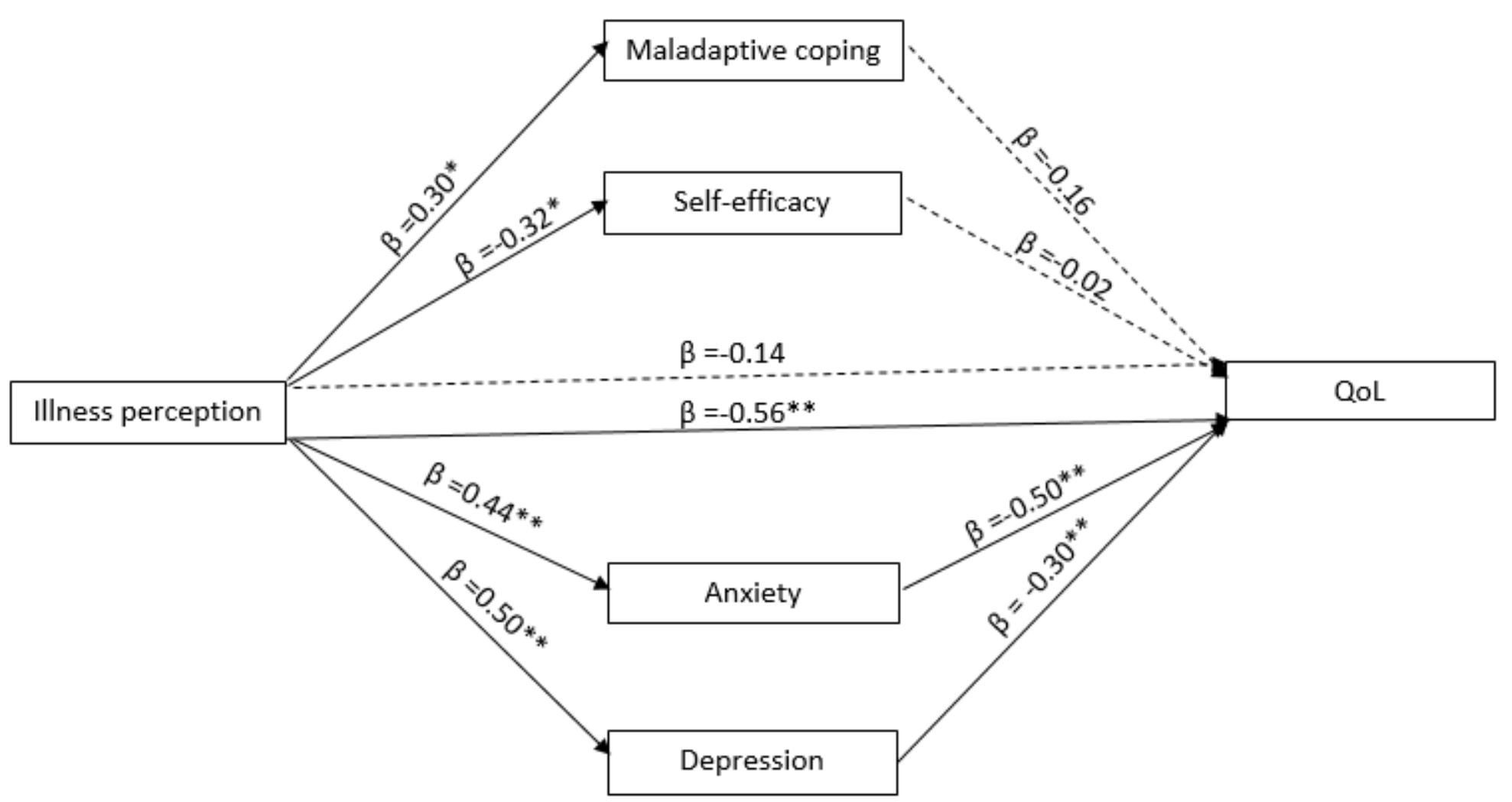

Figure 1. Multiple mediation between illness perception and QoL $\left({ }^{*} p<0.05,{ }^{* *} p<0.001\right)$. 